\title{
Molecular Endoscopy and in vivo Imaging in Inflammatory Bowel Diseases
}

\author{
Markus F. Neurath \\ Department of Medicine 1, University of Erlangen-Nuremberg, Kussmaul Campus for Medical Research and \\ Translational Research Center, Erlangen, Germany
}

\section{Key Words}

Inflammatory bowel disease - Cytokines - Endoscopy .

Molecular imaging · Tumor necrosis factor

\begin{abstract}
Background: Studies in recent years have shown that standard imaging modalities such as endoscopy, ultrasonography or MRI are essential for assessment of gut inflammation in patients with inflammatory bowel diseases (IBDs). In addition, endoscopy plays a pivotal role in the analysis of mucosal healing in these disorders. However, these techniques do not allow a detailed analysis of the molecular pathways driving gut inflammation in IBD patients. Here, we discuss the role of new techniques for the molecular imaging of gut inflammation in IBD with special reference to the prediction of responses to therapy using antibodies to tumor necrosis factor (anti-TNF). Key Messages: Several in vivo imaging studies have been performed in IBD patients before and after antiTNF therapy. In one study, (99m)Technetium-labeled annexin $\mathrm{V}$ was given to patients with active Crohn's disease before and after anti-TNF therapy with infliximab. Subsequently, single-photon emission CT (SPECT) was performed to study the effect of anti-TNF treatment on apoptosis in the intestine during active colitis. This study showed enrichment of technetium signals in the gut of patients who responded to antiTNF therapy. The findings suggested that anti-TNF treatment induces T-cell apoptosis in vivo and that SPECT imaging can be used for prediction of response to anti-TNF therapy. In another study, fluorescent anti-TNF antibodies
\end{abstract}

(fluorescent adalimumab) were chosen for molecular imaging during confocal laser endomicroscopy in patients with active Crohn's disease. This study revealed that an increase of membrane-bound TNF expressing mucosal immune cells predicts response to subsequent adalimumab therapy. Conclusions: Molecular in vivo imaging is an exciting new field in patients with IBD. It is expected that this field will allow new insights into the pathophysiology of IBD and may be used for personalized medicine in the future.

c) 2015 S. Karger AG, Basel

\section{Introduction}

Inflammatory bowel diseases (IBDs) such as Crohn's disease and ulcerative colitis are chronic inflammatory disorders of the gut [1-3]. In these diseases, mucosal immune cells appear to be activated by the commensal microflora in a genetically susceptible host leading to uncontrolled proinflammatory cytokine production and subsequent tissue destruction [4-8]. Complications of IBD may comprise development of stenoses, stricture formation, abscesses, fistulas and colitis-associated colon cancer $[2,9]$. Imaging of gut inflammation in IBD is essential for the diagnosis of IBD, assessment of IBD-associated complications and may help to guide optimized

This work was supported by the Clinical Research Group 257 CEDER of the Deutsche Forschungsgemeinschaft.

\section{KARGER 125}

(C) 2015 S. Karger AG, Basel

$0257-2753 / 15 / 0335-0032 \$ 39.50 / 0$
Markus F. Neurath, MD

Medical Clinic 1

Friedrich-Alexander Universität Erlangen-Nürnberg

Ulmenweg 18, DE-91054 Erlangen (Germany)

E-Mail markus.neurath@uk-erlangen.de 
therapy. In particular, studies in recent years have shown that standard imaging modalities such as endoscopy, ultrasonography, CT or MRI are useful tools for the assessment of gut inflammation in IBD [10-14].

Endoscopy can be used to identify inflamed regions of the bowel wall in IBD and is routinely used for the generation of biopsies from inflamed areas of the gut. Furthermore, endoscopy can be used for the assessment of mucosal healing both in patients with Crohn's disease and ulcerative colitis [15-19]. In addition, advanced endoscopic techniques including dye-less chromoendoscopy, capsule endoscopy and double balloon enteroscopy have been tested for the detection of IBD lesions in the small intestine [20, 21]. Finally, advanced technologies such as dye-based chromoendoscopy as well as standard endoscopy with random biopsies have been used for the detection of flat neoplasias and early cancers in the colon of IBD patients [21,22]. Thus, endoscopy plays an important role in the management of patients with IBD and has also recently been used for imaging of inflammatory lesions in murine models of IBD $[23,24]$. In addition, confocal laser endomicroscopy has been introduced as a new technique for cell imaging during ongoing endoscopy in mice and humans $[25,26]$. This approach permits the analysis of single cells in the bowel wall and allows subsurface imaging of the mucosa in IBD patients [27].

In addition to endoscopy, ultrasonography, CT and MRI are widely used for evaluation of gut inflammation in IBD $[11,12,28,29]$. These 3 techniques have a high comparable diagnostic accuracy for the detection of lesions in IBD. Although the key limitations of ultrasonography consist of the anatomic location of the lesions and the expertise of the examiner, it should be pointed out that this technique is safe, cheap and can be repeated many times. In contrast, the key limitation of CT relates to radiation exposure of patients. Thus, this technique is usually performed in emergency situations to exclude major complications of IBD. Finally, MRI has been used for the evaluation of both the small and the large bowels in IBD patients, particularly in patients with Crohn's disease [12]. MRI permits high spatial and tissue resolution in IBD patients with no ionizing radiation. Recent studies suggest that this technique has a high diagnostic accuracy for assessing disease activity and location in these patients. In particular, MRI has been helpful in monitoring the penetrating and structuring lesions in patients with Crohn's disease [30, 31 ] and is now routinely performed in many centers. In addition to MRI, 18F-fluordesoxyglucose positron emission tomography has been used for the analysis of inflamed bowel segments in IBD. This technique showed promise

Molecular Endoscopy and in vivo Imaging in IBDs in accurate assessment of disease compared to endoscopy but is associated with radiation [32-34]. Therefore, this technique is currently not being routinely used for the assessment of gut inflammation in IBD patients.

The above-mentioned techniques provide important insights into the anatomical segments of the gut that are affected by inflammation in IBD. However, they do not allow insights into the molecular nature of the signaling events that drive gut inflammation in these disorders. This problem may be solved by the introduction of molecular imaging in IBD patients. Molecular imaging is a technique that involves imaging of surface molecules, intracellular signaling molecules and soluble mediators such as cytokines in order to identify molecular targets for therapy or to understand molecular signaling events in vivo [35-37]. This technique is critically dependent on the availability of suitable molecular beacons or probes that can be used for in vivo imaging. Furthermore, suitable imaging devices for in vivo detection of the molecular probes are required [38]. Such molecular imaging has been widely explored in experimental animal models of gut inflammation and cancer, in vivo and ex vivo, and most molecular probes depend on fluorescein detection systems. Examples include the detection of vascular endothelial growth factor on gastrointestinal tumor cells [39], the identification of neoplastic cells in the human colon by using a fluorescent heptapeptide [40] and the analysis of colonic neoplasias in mice by using an enzymatically activatable probe that fluoresces in the presence of the cancer-associated enzyme gamma-glutamyl transpeptidase [38]. Such imaging can be used for early diagnosis of neoplastic and inflammatory lesions in the gastrointestinal tract. Moreover, it may be used for identification of targets for therapy and optimized treatment of inflammation and cancer.

\section{Results}

The following part summarizes the current literature: Antibodies to tumor necrosis factor (anti-TNF) play a pivotal role in the treatment of IBD [2, 9, 41-44]. However, their molecular mechanisms of action have only been partially characterized [45]. Clinically effective anti-TNF antibodies such as infliximab, adalimumab and golimumab bind to both soluble and membrane-bound forms of TNF and may thereby induce immunosuppression [46-48]. In particular, binding of anti-TNF antibodies appears to induce programmed cell death or apoptosis of immune cells such as T-lymphocytes by binding to membrane-bound 
Fig. 1. The mTNF/TNFR2 signaling pathway in IBD. Mucosal immune cells such as CD14+ macrophages express mTNF on their surface that provides an important co-stimulatory stimulus for mucosal T-cells expressing the mTNF receptor TNFR2. Subsequently, T-cells are activated and they produce cytokines such as IL-6 upon TRAF2 activation. Blockade of the mTNF/TNFR2 signaling pathway inhibits co-stimulation of T-cells and results in Tcell apoptosis. Modified according to [47, 51].

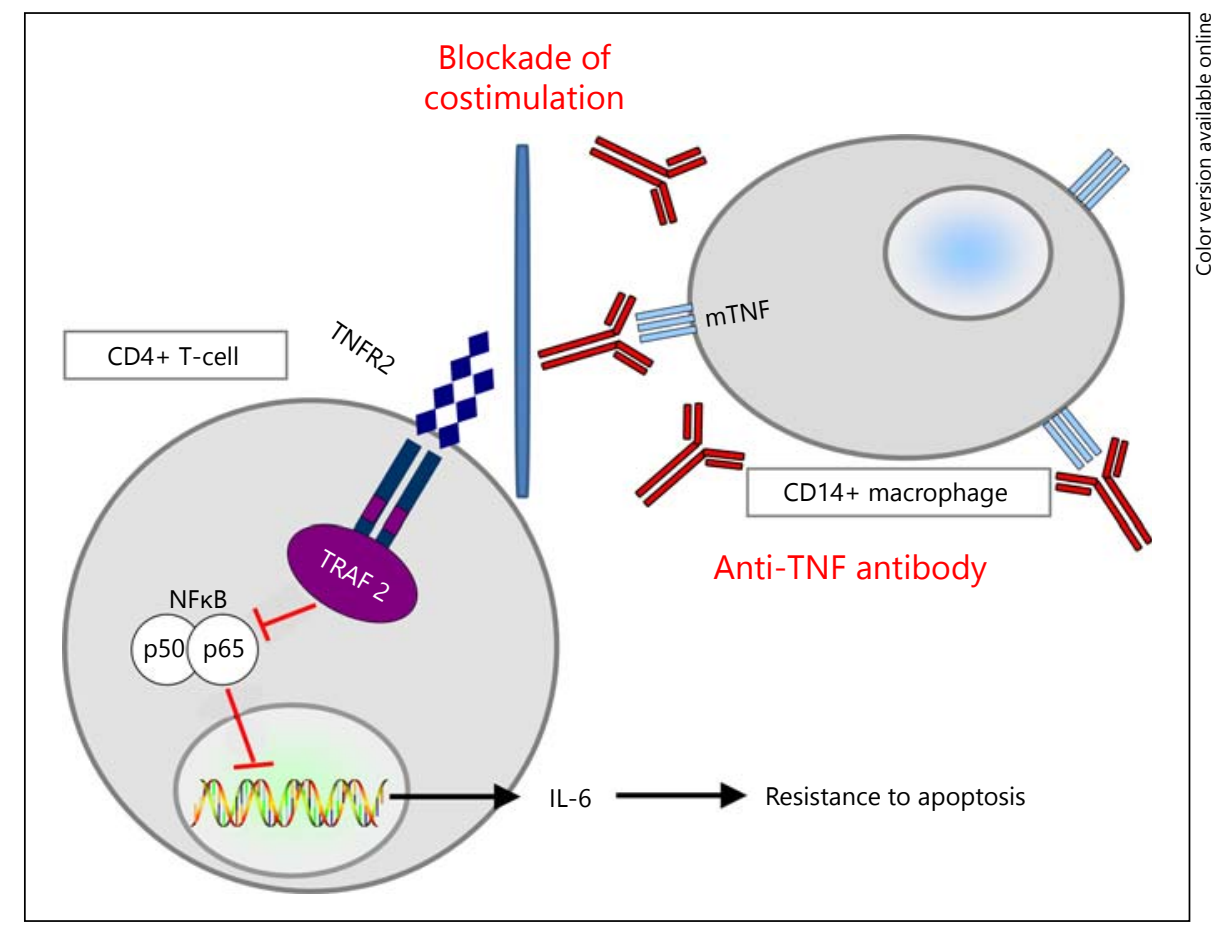

TNF (mTNF; fig. 1). Upon binding of anti-TNF antibodies to mTNF on immune cells such as mucosal CD14+ macrophages, suppression of mTNF-mediated co-stimulation of T-cells is found, because anti-TNF antibodies block the binding of mTNF to its receptor TNFR2 on T-cells. Subsequently, T-cells undergo programmed cell death in the mucosa. Therefore, anti-TNF therapy in IBD may lead to removal of inflammatory immune cells in the mucosa.

Two recent studies have used in vivo imaging technologies to analyze the effects of anti-TNF antibodies in patients with Crohn's disease. The first study had used in vivo imaging for the detection of apoptotic immune cells in the gastrointestinal tract of patients with Crohn's disease before and after treatment with the anti-TNF antibody infliximab [49]. In this study, 14 patients with active Crohn's disease were administered with (99m)Technetium-labeled annexin V ((99m)Tc-annexin V) followed by single-photon emission CT for the detection of apoptotic cells. In anti-TNF responders, it was found that the uptake of $(99 \mathrm{~m}) \mathrm{Tc}$-annexin $\mathrm{V}$ had significantly increased in the bowel wall of patients with active Crohn's disease after treatment with infliximab. In contrast, little or no increase of uptake was observed in anti-TNF non-responders. A mean increase of $98.7 \%$ in colonic uptake of $(99 \mathrm{~m}) \mathrm{Tc}$-annexin $\mathrm{V}$ was found in anti-TNF responders as compared with $15.2 \%$ in non-responding patients suggesting that successful infliximab therapy is associated with the induction of apoptosis of mucosal immune cells. Further studies on mucosal biopsies revealed that mainly T-cells undergo apoptosis upon anti-TNF treatment and that the induction of apoptosis correlates with the clinical response to anti-TNF therapy in Crohn's disease. Collectively, these results indicated that the colonic uptake of $(99 \mathrm{~m}) \mathrm{Tc}$-annexin $\mathrm{V}$ during in vivo imaging correlates with clinical benefit of anti-TNF treatment in this disease.

The second study on anti-TNF therapy analyzed the presence of $\mathrm{mTNF}$, expressing immune cells in the mucosa of 25 patients with Crohn's disease using in vivo molecular imaging [50]. This study used fluorescent adalimumab antibodies for the in vivo analysis of mTNF immune cells during ongoing endoscopy with confocal laser endomicroscopy. Topical administration of fluorescent adalimumab led to the detection of mTNF expressing immune cells in the mucosa, as shown by confocal endomicroscopy. There was a marked variability of mTNF immune cells among the individual patients, and 2 subgroups of patients with Crohn's disease (high mTNF group vs. low mTNF group) could be clearly differentiated based on quantitative image analyses. However, subsequent therapy with adalimumab subcutaneously revealed different clinical responses to anti-TNF therapy between the 2 groups. The high mTNF group showed excellent clinical responses and mucosal healing upon antiTNF therapy, whereas the low mTNF group showed poor 
clinical responses to adalimumab therapy. These findings suggested that the molecular imaging with fluorescent adalimumab permits prediction of clinical responses to anti-TNF therapy. However, this concept requires additional prospective studies in larger patient cohorts.
This concept opens new avenues for optimized diagnosis and therapy of IBD. It is expected that this field will allow new insights into the pathophysiology of IBD and may be used for personalized medicine in the future by the detailed mapping of relevant immune signaling pathways in individual patients.

\section{Conclusions}

In summary, the current findings clearly demonstrate that in vivo imaging using molecular endoscopy has become a clinical reality for IBD patients in clinical trials.

\section{Disclosure Statement}

M.F.N. has served as advisor for Pentax, MSD, Abbvie and Giuliani.

\section{References}

1 Macdonald TT, Monteleone G: Immunity, inflammation, and allergy in the gut. Science 2005;307:1920-1925.

2 Baumgart DC, Sandborn WJ: Crohn's disease. Lancet 2012;380:1590-1605.

3 Strober W, Fuss IJ, Blumberg RS: The immunology of mucosal models of inflammation. Annu Rev Immunol 2002;20:495-549.

4 Monteleone G, Pallone F, MacDonald TT: Emerging immunological targets in inflammatory bowel disease. Curr Opin Pharmacol 2011;11:640-645.

5 Monteleone I, Sarra M, Pallone F, Monteleone G: Th17-related cytokines in inflammatory bowel diseases: friends or foes? Curr Mol Med 2012;12:592-597.

6 Atreya R, Mudter J, Finotto S, Mullberg J, Jostock T, Wirtz S, et al: Blockade of interleukin 6 trans signaling suppresses T-cell resistance against apoptosis in chronic intestinal inflammation: evidence in crohn disease and experimental colitis in vivo. Nat Med 2000;6:583588.

7 Gerlach K, Hwang Y, Nikolaev A, Atreya R, Dornhoff $\mathrm{H}$, Steiner $\mathrm{S}$, et al: TH9 cells that express the transcription factor PU.1 drive T cell-mediated colitis via IL-9 receptor signaling in intestinal epithelial cells. Nat Immunol 2014;15:676-686

8 Sandborn WJ, Ghosh S, Panes J, Vranic I, Su C, Rousell S, et al: Tofacitinib, an oral Janus kinase inhibitor, in active ulcerative colitis. $\mathrm{N}$ Engl J Med 2012;367:616-624.

9 Danese S, Fiocchi C: Ulcerative colitis. N Engl J Med 2011;365:1713-1725.

10 Tontini GE, Vecchi M, Pastorelli L, Neurath MF, Neumann H: Differential diagnosis in inflammatory bowel disease colitis: state of the art and future perspectives. World J Gastroenterol 2015;21:21-46.

11 Rimola J, Ordas I, Rodriguez S, Panes J: Colonic Crohn's disease: value of magnetic resonance colonography for detection and quantification of disease activity. Abdom Imaging 2010;35:422-427.
12 Rimola J, Rodriguez S, Garcia-Bosch O, Ordas I, Ayala E, Aceituno M, et al: Magnetic resonance for assessment of disease activity and severity in ileocolonic Crohn's disease. Gut 2009;58:1113-1120.

13 Herfarth HH, Grunert M, Klebl F, Strauch U, Feuerbach S, Scholmerich J, et al: Frequency and nature of incidental extra-enteric lesions found on magnetic resonance enterography (MR-E) in patients with inflammatory bowel diseases (IBD). PLoS One 2009;4:e4863.

14 Allocca M, Fiorino G, Danese S: Cross-sectional imaging modalities in Crohn's disease. Dig Dis 2013;31:199-201.

15 Neurath MF, Travis SP: Mucosal healing in inflammatory bowel diseases: a systematic review. Gut 2012;61:1619-1635.

16 Pineton de Chambrun G, Peyrin-Biroulet L, Lemann M, Colombel JF: Clinical implications of mucosal healing for the management of IBD. Nat Rev Gastroenterol Hepatol 2010; 7:15-29.

17 Baert F, Moortgat L, Van Assche G, Caenepeel P, Vergauwe P, De Vos M, et al: Mucosal healing predicts sustained clinical remission in patients with early-stage Crohn's disease. Gastroenterology 2010;138:463-468; quiz e10-e11.

18 Colombel JF, Rutgeerts P, Reinisch W, Esser D, Wang Y, Lang Y, et al: Early mucosal healing with infliximab is associated with improved long-term clinical outcomes in ulcerative colitis. Gastroenterology 2011;141: 1194-1201.

19 Schnitzler F, Fidder H, Ferrante M, Noman M, Arijs I, Van Assche G, et al: Mucosal healing predicts long-term outcome of maintenance therapy with infliximab in Crohn's disease. Inflamm Bowel Dis 2009;15:12951301.

20 Takenaka K, Ohtsuka K, Kitazume Y, Nagahori M, Fujii T, Saito E, et al: Comparison of magnetic resonance and balloon enteroscopic examination of the small intestine in patients with Crohn's disease. Gastroenterology 2014; 147:334-342.e3.

21 Tontini GE, Vecchi M, Neurath MF, Neumann $\mathrm{H}$ : Advanced endoscopic imaging techniques in Crohn's disease. J Crohns Colitis 2014:8:261-269.

22 Kiesslich R, Fritsch J, Holtmann M, Koehler $\mathrm{HH}$, Stolte M, Kanzler S, et al: Methylene blue-aided chromoendoscopy for the detection of intraepithelial neoplasia and colon cancer in ulcerative colitis. Gastroenterology 2003; $124: 880-888$.

23 Becker C, Fantini MC, Neurath MF: High resolution colonoscopy in live mice. Nat Protoc 2006;1:2900-2904.

24 Waldner MJ, Wirtz S, Jefremow A, Warntjen $M$, Neufert C, Atreya R, et al: VEGF receptor signaling links inflammation and tumorigenesis in colitis-associated cancer. J Exp Med 2010;207:2855-2868.

25 Kiesslich R, Burg J, Vieth M, Gnaendiger J, Enders M, Delaney P, et al: Confocal laser endoscopy for diagnosing intraepithelial neoplasias and colorectal cancer in vivo. Gastroenterology 2004;127:706-713.

26 Waldner MJ, Wirtz S, Neufert C, Becker C, Neurath MF: Confocal laser endomicroscopy and narrow-band imaging-aided endoscopy for in vivo imaging of colitis and colon cancer in mice. Nat Protoc 2011;6:14711481.

27 Neumann H, Neurath MF, Mudter J: New endoscopic approaches in IBD. World J Gastroenterol 2011;17:63-68.

28 Dambha F, Tanner J, Carroll N: Diagnostic imaging in Crohn's disease: what is the new gold standard? Best Pract Res Clin Gastroenterol 2014;28:421-436.

29 Qiu Y, Mao R, Chen BL, Li XH, He Y, Zeng $\mathrm{ZR}$, et al: Systematic review with meta-analysis: magnetic resonance enterography vs. computed tomography enterography for evaluating disease activity in small bowel Crohn's disease. Aliment Pharmacol Ther 2014;40:134-146. 
30 Ordas I, Rimola J, Garcia-Bosch O, Rodriguez S, Gallego M, Etchevers MJ, et al: Diagnostic accuracy of magnetic resonance colonography for the evaluation of disease activity and severity in ulcerative colitis: a prospective study. Gut 2013;62:1566-1572.

31 Ordas I, Rimola J, Rodriguez S, Gallego M, Ricart E, Panes J: Imaging of the colon in inflammatory bowel disease: ready for prime time? Curr Drug Targets 2012;13:12521260.

32 Perlman SB, Hall BS, Reichelderfer M: PET/ CT imaging of inflammatory bowel disease. Semin Nucl Med 2013;43:420-426.

33 Neurath MF, Vehling D, Schunk K, Holtmann $\mathrm{M}$, Brockmann $\mathrm{H}$, Helisch $\mathrm{A}$, et al: Noninvasive assessment of Crohn's disease activity: a comparison of $18 \mathrm{~F}$-fluorodeoxyglucose positron emission tomography, hydromagnetic resonance imaging, and granulocyte scintigraphy with labeled antibodies. Am J Gastroenterol 2002;97:1978-1985.

34 Holtmann MH, Uenzen M, Helisch A, Dahmen A, Mudter J, Goetz M, et al: 18F-Fluorodeoxyglucose positron-emission tomography (PET) can be used to assess inflammation non-invasively in Crohn's disease. Dig Dis Sci 2012;57:2658-2668.

35 Heryanto YD, Achmad A, Taketomi-Takahashi A, Tsushima Y: In vivo molecular imaging of cancer stem cells. Am J Nucl Med Mol Imaging 2014;5:14-26.

36 Wang Y, Tseng JC, Sun Y, Beck AH, Kung AL: Noninvasive imaging of tumor burden and molecular pathways in mouse models of cancer. Cold Spring Harb Protoc 2015;2015:135144.
37 Kim SY, Myung SJ: Optical molecular imaging for diagnosing intestinal diseases. Clin Endosc 2013;46:620-626.

38 Mitsunaga M, Kosaka N, Choyke PL, Young MR, Dextras CR, Saud SM, et al: Fluorescence endoscopic detection of murine colitis-associated colon cancer by topically applied enzymatically rapid-activatable probe. Gut 2013; 62:1179-1186.

39 Foersch S, Kiesslich R, Waldner MJ, Delaney P, Galle PR, Neurath MF, et al: Molecular imaging of VEGF in gastrointestinal cancer in vivo using confocal laser endomicroscopy. Gut 2010;59:1046-1055.

40 Hsiung PL, Hardy J, Friedland S, Soetikno R, $\mathrm{Du}$ CB, Wu AP, et al: Detection of colonic dysplasia in vivo using a targeted heptapeptide and confocal microendoscopy. Nat Med 2008; 14:454-458.

41 Present DH: Review article: the efficacy of infliximab in Crohn's disease - healing of fistulae. Aliment Pharmacol Ther 1999;13(suppl 4):23-28; discussion 38.

42 Rutgeerts P, Vermeire S, Van Assche G: Predicting the response to infliximab from trough serum levels. Gut 2010;59:7-8.

43 Sandborn WJ, Feagan BG, Marano C, Zhang $\mathrm{H}$, Strauss R, Johanns J, et al: Subcutaneous golimumab induces clinical response and remission in patients with moderate-to-severe ulcerative colitis. Gastroenterology 2014;146 85-95; quiz e14-e15.

44 Colombel JF, Sandborn WJ, Reinisch W, Mantzaris GJ, Kornbluth A, Rachmilewitz D, et al: Infliximab, azathioprine, or combination therapy for Crohn's disease. N Engl J Med 2010;362:1383-1395.
45 Neurath MF: Cytokines in inflammatory bowel disease. Nat Rev Immunol 2014;14: 329-342.

46 Mitoma H, Horiuchi T, Hatta N, Tsukamoto H, Harashima S, Kikuchi Y, et al: Infliximab induces potent anti-inflammatory responses by outside-to-inside signals through transmembrane TNF-alpha. Gastroenterology 2005; 128:376-392.

47 Atreya R, Zimmer M, Bartsch B, Waldner MJ, Atreya I, Neumann $\mathrm{H}$, et al: Antibodies against tumor necrosis factor (TNF) induce T-cell apoptosis in patients with inflammatory bowel diseases via TNF receptor 2 and intestinal $\mathrm{CD}_{14}{ }^{+}$macrophages. Gastroenterology 2011;141:2026-2038.

48 Van den Brande JM, Braat $\mathrm{H}$, van den Brink GR, Versteeg HH, Bauer CA, Hoedemaeker I, et al: Infliximab but not etanercept induces apoptosis in lamina propria T-lymphocytes from patients with Crohn's disease. Gastroenterology 2003;124:1774-1785.

49 Van den Brande JM, Koehler TC, Zelinkova Z, Bennink RJ, te Velde AA, ten Cate FJ, et al: Prediction of antitumour necrosis factor clinical efficacy by real-time visualisation of apoptosis in patients with Crohn's disease. Gut 2007;56:509-517.

50 Atreya R, Neumann H, Neufert C, Waldner MJ, Billmeier U, Zopf Y, et al: In vivo imaging using fluorescent antibodies to tumor necrosis factor predicts therapeutic response in Crohn's disease. Nat Med 2014;20:313318.

51 Neurath MF: New targets for mucosal healing and therapy in inflammatory bowel diseases. Mucosal Immunol 2014;7:6-19. 